\title{
A CLINICAL TRIAL OF RAUWOLFIA SERPENTINA IN ESSENTIAL HYPERTENSION
}

\author{
BY \\ RUSTOM JAL VAKIL \\ From the Cardiological Department, King Edward Memorial Hospital, Bombay, India
}

Received January 4, 1949

In a casual perusal of papers on hypertension, one comes across well over a hundred so-called hypotensive remedies alleged to possess the property of lowering the blood pressure. In 1930, Ayman could collect over two hundred reports on the successful treatment of hyperpiesia by various hypotensive remedies.

In view of the persistently high mortality from hypertension in spite of the large number of measures recommended in the treatment of this disease one is forced to admit the futility or helplessness of the situation. In Ayman's opinion, the "proper treatment is still unknown." Evans and Loughnan, . after a critical analysis and trial of thirty-three different preparations in seventy cases of high blood pressure (essential hypertension), were forced to admit the uselessness of them all. In their opinion, simple sedative measures are often more effective than the much more expensive and fashionable products extensively displayed on the market.

There is unfortunately, a great tendency on the part of both the medical profession and the laiety, to hail or applaud any new drug or measure introduced into the market, often on the basis of a few stray experiences or clinical impressions. In consequence of this attitude, many of the present day clinicians have learnt not to accept any claim for a new remedy unless and until its therapeutic value has been firmly established by resort to carefully controlled clinical observations.

My selection of $R$. Serpentina for the present study has not been entirely fortuitous. I have been prompted into the present enquiry by several factors. In the short span of ten years that the dried root of $R$. Serpentina has been on the market in India, in tablet form, there has been a growing demand in this country for these tablets. Preparations of the serpentina root have gained such unprecedented popularity for hypertension cases in this country, that there is hardly a patient with high blood pressure who has not been subjected to its effects in one form or another. One manufacturing firm alone claims to have sold over 50 million tablets of the dried root. One of the aims of the present investigations has therefore been to determine if this enthusiastic reception of the drug is warranted. As early as 1940 , I had made the following allusion to the subject of $R$. Serpentina treatment in cases of hypertension: "After a trial of this preparation one finds it useful in a percentage of cases of hypertension only; the indications and suitability of the case for the drug have not as yet been worked out." Since that time, I have had the opportunity of observing the effects of this drug in a very large number of cases. After an extensive trial of various hypotensive remedies in several thousand cases of hypertension, both in private and hospital practice during the last ten years, I have found $R$. Serpentina to be the most consistently successful member of the whole group of hypotensive remedies. In reply to a recent questionnaire issued by me to fifty physicians from all over India, forty-six voted for $R$. Serpentina as being the best " hypotensive" in their experience.

In view of this overwhelming body of support in favour of regarding $R$. Serpentina as the remedy of choice, I have considered it opportune to subject this preparation to a more critical analysis and to try and form an unbiased opinion of its value as a hypotensive agent. In the present investigation I have tried to steer clear of those fallacies involved in the interpretation of therapeutic results, to which particular attention has been drawn by Ayman, Kapernick, and others. There is an unfortunate tendency to claim success in the treatment of essential hypertension merely on the basis of symptomatic improvement. In the opinion of Ayman, the successful treatment of hyperpiesia, implies, of neces- 
sity, a substantial reduction in the level of the blood pressure. In Kapernick's opinion, " although symptomatic response is relatively easily obtained, reduction of blood pressure is difficult." This has been the experience also of Evans and Loughnan, who found that although good symptomatic relief can be obtained in cases of hypertension with a large number of remedies, the much more desirable hypotensive effect is rarely noted. The factor of natural lability of the blood pressure, so common in hypertensives, is often lost sight of, in the interpretation of results; as a result, perfectly normal or natural fluctuations are mistaken or misconstrued for evidences of the therapeutic value of the drug under trial.

According to Evans and Loughnan, any remedy before it can be accepted as having established a claim as a hypotensive agent must satisfy certain standards of efficiency, viz. (1) it should be capable both of reducing a blood pressure that is high and of maintaining it at the lowered value; (2) it should be able to exhibit its hypotensive action consistently and in a high proportion of patients; and (3) it should be free of all toxic ill-effects.

\section{An Introduction to Rauwolfia Serpentina}

The use of vegetable extracts in the treatment of high blood pressure is not new. Both, watermelon seeds and the mistletoe plant have been tried in the past, without gaining general endorsement. In 1939, Graham had reported benefit in cases of hypertension from the use of the tincture of hawthorne (Cratagus oxycantha).

$R$. Serpentina (variously known in India as sarpagandha, chandrika, chotachand, chandra, dhanmarna, dhan-barua, patala-gandhi, and covanamilpori) or the Serpentina plant is a large climbing or twining herb or shrub, belonging to the natural order Apocynacea, and found in the Himalayas, in Assam, Pegu, Tennasserim, Java, the Deccan peninsula, and the Malaya peninsula.

The root of this plant has been popular, both in India and in the Malay peninsula, from ancient times, as an antidote to the stings and bites of insects and poisonous reptiles. It has been used also as a febrifuge, as a stimulant to uterine contractions, for insomnia, and most of all for insanity. More recently, its clinical application has been extended, with success, to cases of high blood pressure.

Early researches on $R$. Serpentina showed that it contained an alkaloid which was provisionally called pseudobrucine. On account of its popularity with practitioners of indigenous medicine, the chemical composition of the serpentina plant has been subjected to considerable scrutiny. Sen and Bose (1931) discovered two alkaloids in its root, the total alkaloid content being about 1 per cent of the dried root, there being also a lot of resin and starch. Siddiqui and Siddiqui (1931) found, besides phytosterol, oleic acid, and unsaturated alcohols, five alkaloids, which were classified by them into two groups, viz. (1) The ajmaline group of three white crystalline, weak bases, ajmaline, ajmalinine, ajmalicine; and (2) the serpentine group of two yellow crystalline stronger bases, serpentine and serpentinine.

On the basis of experiments on frogs, Siddiqui and Siddiqui showed that the ajmaline group acts as a general depressant to the heart, respiration, and central nervous system, whilst the serpentine group causes paralysis of respiration, depression of nerves, and stimulation of the heart. Sen and Bose studied the pharmacological effects of the $R$. Serpentina alkaloids on cats and other higher animals. They reported a small drop of blood pressure, a stimulation of the respiration, a depression of the heart muscle and a relaxation of plain muscle-tissue (e.g. of the uterus and intestines). Roy (1931) found that large doses induce sleep, cause dulling of sensations and diminution of reflexes. Fatal doses caused death from respiratory failure the heart continuing to beat for some time after. Chopra has been engaged in pharmacological researches on the $R$. Serpentina since 1932, but the results of his work are not as yet known. It is claimed by certain manufacturers that the root from a well-reared and scientifically cultivated serpentina plant yields about three times more of the active alkaloids than the root from the wild plant, which is thinner, more stunted and often marred by exposure to the sun, rain, and frost.

On the basis of experimental and clinical studies, the root of $R$. Serpentina is said to have the following pharmacological attributes. (1) By action on the vaso-motor centre, it leads to generalized vasodilatation, with a lowering of blood pressure. (2) By depressant action on the cerebral centres, it soothes the general nervous system. (3) It exerts a sedative action on the gastric mucosa and a stimulating action on the plain musculature of the intestinal tract. (4) It stimulates the bronchial musculature.

A vague reference to the use of a tincture or alcoholic extract of the root of $R$. Serpentina, in cases of high blood pressure, was made in 1942 by Paranjpe. He claimed improvement, without any statistical backing, in most cases of hypertension; the hypotensive action was said to be particularly gratifying in elderly subjects and in the case of the diastolic pressure; the tincture was said to be a 
good cough-sedative and diuretic. In two cases reported by Paranjpe, there had been a permanent reduction of blood pressure for well over a year, on occasional doses of the tincture.

\section{Method of INVESTIGATION}

Selection of patients. The fifty patients for investigation were selected from amongst a large number of cases of essential hypertension, who reported regularly at the clinic for treatment and who showed their willingness to co-operate. The diagnosis of essential hypertension was accepted on the basis of a routine clinical examination and investigations including urine analysis, ophthalmoscopic examination, orthodiagraphy, electrocardiography, and (in some cases) renal function tests and teleradiography. Only patients with systolic pressure over 160 and diastolic over $95 \mathrm{~mm}$. were admitted into this series. Cases of nephritic or renal hypertension, secondary hypertension, and malignant hypertension (diagnosed on the basis of clinical and ocular criteria) were rigidly excluded. Of the 50 patients selected for study, 30 were males and 20 females, ranging in age from 39 to 76 years, the average age for the series being 59 years.

Each patient was instructed to report for examination periodically, according to a rigid and prearranged plan. The routine adopted in each case was identical, viz. after an initial examination and check-up of the blood pressure (reading A), the patient was kept on a sedative capsule (containing 0.25 grains of prominal or phemitone) given three times daily for two weeks, the blood pressure being recorded again (reading B) and accepted as the actual "pre-treatment" level. This preparatory period of sedation exerts in my opinion a sort of stabilizing influence on the blood pressure of hypertensives, especially in those with hypersensitive nervous systems. Administration of $R$. Serpentina tablets (one serpina tablet three times a day after meals) was then started, this dose being kept up for four weeks. The only other preparations permitted, during $R$. Serpentina therapy, were laxatives, insulin injections (in diabetics), and occasionally tablets of aspirin for headaches. During serpina treatment, the blood pressure was checked and recorded once weekly (readings $C, D, E$, and F). In a few of my cases, the fall was so precipitate that further treatment had to be discontinued. After four weeks of serpina treatment, all medication was stopped for four weeks; during this interval or period of no treatment, the blood pressure was recorded twice, at fortnightly intervals (readings $\mathbf{G}$ and $\mathrm{H}$ ). A second course of serpina tablets (in the same doses) was then started and continued for two weeks; at the end of this course, the blood pressure was recorded for the last time (reading J). The following nine sets of blood pressure readings were, therefore, recorded in each case: (A) at start of investigation, (B) after two weeks of sedative therapy, (C) after one week of serpina therapy, (D) after two weeks of therapy, (E) after three weeks of therapy, (F) after four weeks of therapy, (G) after a fortnight of no medication, (H) after four weeks of no medication, and (J) after two weeks of serpina treatment (second course).

The ritual observed at each check-up of the patient was properly standardized. At each attendance (arranged between the hours of 3 and 6 p.m.), the patient was made to rest in the waiting room for about half an hour. After a short history of symptoms and an enquiry for toxic reactions, the patient was subjected to a thorough clinical examination. The blood pressure was recorded in the recumbent posture with the aid of a new Baumanometer, in accordance with the suggestions of the joint British and American Committees for standardization. Of three consecutive readings at each sitting, only the third or last was accepted for recording purposes. All the observations reported here were made by me using the same instrument throughout.

In the present investigation, I have not concerned myself much with the improvement in individual symptoms, reported by patients, such a determination being liable to errors of interpretation. In any case, the symptomatic status of such a case bears little or no relationship to the level of the blood pressure.

In the presentation of results, all rises or falls of systolic blood pressure of less than $10 \mathrm{~mm}$. and of the diastolic of less than $5 \mathrm{~mm}$. have been classified as " insignificant," rises or falls of systolic pressure between 10 and $24 \mathrm{~mm}$. and of the diastolic between 5 and $14 \mathrm{~mm}$. as " moderate" and rises or falls of the systolic exceeding $25 \mathrm{~mm}$. and of the diastolic exceeding $15 \mathrm{~mm}$. have been classified as "marked."

\section{RESUlts of INVESTIGATION}

After two weeks of sedative therapy. After two weeks 28 of 50 patients showed a drop of systolic pressure ranging from 2 to $12 \mathrm{~mm}$., the average fall being $6 \mathrm{~mm}$. In 17 of the cases there was a rise ranging from 2 to $14 \mathrm{~mm}$., with an average of $4 \mathrm{~mm}$. In the remaining 5 cases, there was no alteration at all. Taking all 50 cases into consideration, the average drop of systolic blood pressure after two weeks of sedation works out at under $2 \mathrm{~mm}$.

In the case of the diastolic blood pressure, there was a fall in 30 cases ranging from 2 to $8 \mathrm{~mm}$. with an average of $3 \mathrm{~mm}$; in 7 cases there wa 
an actual rise ranging from 2 to $10 \mathrm{~mm}$., with an average of $4 \mathrm{~mm}$.

\section{After One Week of R. Serpentina Therapy}

The immediate response of the blood pressure to $\boldsymbol{R}$. Serpentina therapy is shown in Table I.

\section{TABLE I}

Changes of Systolic and Diastolic Blood Pressure after One Week of R. Serpentina Therapy

\begin{tabular}{|c|c|c|c|c|}
\hline \multirow{2}{*}{$\begin{array}{l}\text { Extent of alteration } \\
\text { in blood pressure }\end{array}$} & \multicolumn{2}{|c|}{$\begin{array}{c}\text { Systolic blood } \\
\text { pressure }\end{array}$} & \multicolumn{2}{|c|}{$\begin{array}{c}\text { Diastolic } \\
\text { blood pressure }\end{array}$} \\
\hline & $\begin{array}{l}\text { No. of } \\
\text { cases }\end{array}$ & $\begin{array}{l}\text { Per } \\
\text { cent }\end{array}$ & $\begin{array}{l}\text { No. of } \\
\text { cases }\end{array}$ & $\begin{array}{l}\text { Per } \\
\text { cent }\end{array}$ \\
\hline $\begin{array}{r}\text { From }+10 \text { to }+6 \mathrm{~mm} \text {. } \\
+5 \text { to }+1 \mathrm{~mm} \text {. } \\
\text { No change- }-4 \mathrm{~mm} . \\
-1 \text { to }-4 \text { to }-9 \mathrm{~mm} \text {. } \\
-10 \text { to }-14 \mathrm{~mm} \text {. } \\
-15 \text { to }-19 \mathrm{~mm} \text {. } \\
-20 \text { to }-24 \mathrm{~mm} \text {. } \\
-25 \text { to }-29 \mathrm{~mm} \text {. } \\
-30 \text { to }-34 \mathrm{~mm} \text {. } \\
-35 \text { to }-40 \mathrm{~mm} \text {. }\end{array}$ & $\begin{array}{r}1 \\
8 \\
2 \\
7 \\
11 \\
7 \\
2 \\
5 \\
2 \\
2 \\
1\end{array}$ & $\begin{array}{r}2 \\
17 \\
4 \\
15 \\
23 \\
15 \\
4 \\
10 \\
4 \\
4 \\
2\end{array}$ & $\begin{array}{r}1 \\
8 \\
4 \\
18 \\
12 \\
4 \\
1 \\
0 \\
0 \\
0 \\
0\end{array}$ & $\begin{array}{r}2 \\
17 \\
8 \\
38 \\
25 \\
8 \\
2 \\
0 \\
0 \\
0 \\
0\end{array}$ \\
\hline From +10 to $-40 \mathrm{~mm}$. & 48 & 100 & 48 & 100 \\
\hline
\end{tabular}

Systolic blood pressure. Of the 48 cases studied (two of our patients having absented themselves), as many as 37 cases showed a drop of systolic pressure, ranging from 2 to $38 \mathrm{~mm}$. with an average drop of $13 \mathrm{~mm}$. In 2 cases it remained unaltered whilst in 9 there was actually a paradoxical rise, ranging from 2 to $6 \mathrm{~mm}$. with an average rise of $3 \mathrm{~mm}$.

A " moderate" fall (i.e. 10 to $24 \mathrm{~mm}$.) was noted in 14 out of 48 cases and a "marked" fall (i.e. $25 \mathrm{~mm}$. or over) in 5 cases. In other words, of my 48 cases, 19 cases (or $39 \cdot 5$ per cent) showed a response within a week of commencement of serpina treatment.

Diastolic blood pressure. Of the 48 cases, 35 showed a fall of diastolic pressure ranging from 2 to $18 \mathrm{~mm}$., with an average of $6 \mathrm{~mm}$.; in 4 cases the diastolic level remained unaffected whilst in 9 there was an actual rise ranging from 2 to $6 \mathrm{~mm}$. with an average of $3 \mathrm{~mm}$.

The diastolic fall was classified as being of " moderate" degree (i.e. 5 to $14 \mathrm{~mm}$.) in 16 cases and as "marked" (i.e. $15 \mathrm{~mm}$. or over) in 1 case. A good result (i.e. a diastolic drop of $5 \mathrm{~mm}$. or more) was therefore obtained in 17 cases. (See Table I.)
In 35 of my 48 cases, there was a drop of both systolic and diastolic pressure, after one week of drug treatment; in 6 cases there was a paradoxical rise of both systolic and diastolic pressure whilst in the remaining 6 cases there was a rise of one with a fall of the other.

\section{After Four Weeks of R. Serpentina Therapy}

The delayed response of the blood pressure to drug therapy is given in Table II.

\section{TABLE II}

Changes of Systolic and Diastolic Blood Pressure after Four Weeks of R. Serpentina Therapy

\begin{tabular}{|c|c|c|c|c|}
\hline \multirow{2}{*}{$\begin{array}{l}\text { Extent of alteration in } \\
\text { blood pressure } \\
\end{array}$} & \multicolumn{2}{|c|}{$\begin{array}{l}\text { Systolic blood } \\
\text { pressure }\end{array}$} & \multicolumn{2}{|c|}{$\begin{array}{c}\text { Diastolic } \\
\text { blood pressure }\end{array}$} \\
\hline & $\begin{array}{l}\text { No. of } \\
\text { cases }\end{array}$ & $\begin{array}{l}\text { Per } \\
\text { cent }\end{array}$ & $\begin{array}{l}\text { No. of } \\
\text { cases }\end{array}$ & $\begin{array}{l}\text { Per } \\
\text { cent }\end{array}$ \\
\hline $\begin{array}{l}\text { From }+20 \text { to }+11 \mathrm{~mm} \text {. } \\
+10 \text { to }+1 \mathrm{~mm} \text {. } \\
\begin{array}{r}\text { No change- } \\
-1 \text { to }-9 \mathrm{~mm} . \\
-10 \text { to }-19 \mathrm{~mm} \text {. } \\
-20 \text { to }-29 \mathrm{~mm} \text {. } \\
-30 \text { to }-39 \mathrm{~mm} \text {. } \\
-40 \text { to }-49 \mathrm{~mm} \text {. } \\
-50 \text { to }-60 \mathrm{~mm} .\end{array}\end{array}$ & $\begin{array}{r}1 \\
6 \\
0 \\
5 \\
14 \\
9 \\
10 \\
1 \\
1\end{array}$ & $\begin{array}{r}2 \\
13 \\
0 \\
11 \\
30 \\
19 \\
21 \\
2 \\
2\end{array}$ & $\begin{array}{r}0 \\
6 \\
3 \\
17 \\
18 \\
2 \\
1 \\
0 \\
0\end{array}$ & $\begin{array}{r}0 \\
13 \\
7 \\
36 \\
38 \\
4 \\
2 \\
0 \\
0\end{array}$ \\
\hline From +20 to $-60 \mathrm{~mm}$. & 47 & 100 & 47 & 100 \\
\hline
\end{tabular}

Systolic blood pressure. Of the 47 cases studied (three failed to report for check-up), as many as 40 responded to serpina therapy by showing a drop of systolic pressure, ranging from 2 to $54 \mathrm{~mm}$. with an average of $21 \mathrm{~mm}$. A rise of 4 to $12 \mathrm{~mm}$., with an average of $6 \mathrm{~mm}$. was noted in the remaining 7. Taking all the cases into consideration, the average fall worked out at $19 \mathrm{~mm}$., with a range of +12 to $-54 \mathrm{~mm}$.

The systolic fall was described as being " moderate" in 22 cases out of 47 and as " marked" in 13 cases. In other words, a good systolic response (i.e. $10 \mathrm{~mm}$. or over) was noted in 35 of 47 cases, after four weeks of serpina therapy.

Diastolic blood pressure. In 38 out of the 47 cases there was a drop of diastolic pressure ranging from 4 to $34 \mathrm{~mm}$., with an average of $11 \mathrm{~mm}$.; in 3 cases, the diastolic level remained unaltered whilst in 6 cases there was an actual rise varying between 2 and $10 \mathrm{~mm}$., the average being $5 \mathrm{~mm}$. Taking all cases into consideration, the diastolic pressure showed an average drop of $10 \mathrm{~mm}$., the range of variation being from +10 to $-34 \mathrm{~mm}$. 
The diastolic fall, after four weeks of therapy, could be classified as "moderate" in 27 of the 47 cases and as "marked" in 7 cases. A good diastolic response (i.e. $5 \mathrm{~mm}$. or over) was therefore obtained in as many as 34 out of 47 cases.

In as many as 29 of my 47 cases there was a " moderate" or " marked" fall of both systolic and diastolic pressures; in 6 cases such improvement was confined to systolic levels only, and in 2 to the diastolic levels only.

Types of blood pressure response, during $R$. Serpentina therapy. According to the rapidity and degree of fall of the systolic blood pressure during drug treatment, I have been able to recognize five main types of blood pressure curves. (1) A gradual fall continued throughout the course of treatment (21 of my 50 cases). (2) The plateau type, where the systolic level showed little or no alteration throughout treatment (12 cases). (3) A precipitate initial drop with a gradual decline subsequently (8 cases). (4) An initial plateau with subsequently, a gradual decline (5 cases). (5) A precipitate initial drop with subsequently a plateau ( 3 cases).

From the behaviour of the pressure (especially systolic), a graph can easily be constructed to determine the type of response to drug treatment, in any given case.

\section{After Cessation of R. Serpentina Therapy}

These studies were undertaken with a view to determine whether the hypotensive action of serpina is strictly limited to the period of its administration or whether it is continued for some time after.

After two weeks. The persistence of the hypotensive action of $R$. Serpentina was studied in the 41 cases in my series, who had responded to its administration by a fall of blood pressure; unfortunately, 5 of these having failed to report for their periodical check-up, our enquiry has had to be limited to a total of 36 cases. Two weeks after stoppage of serpina treatment, the results were as follows. In 22 of the 36 cases the low levels induced by serpina tablets were well maintained; in 8 cases they were partially maintained; in 3 cases they had returned to their levels of before treatment; in the remaining 3 cases there was a further fall.

After four weeks. Thirty-nine cases could be investigated from this point of view. The results were as follows. In 10 the low levels were well maintained; in 15 cases they were partially maintained; in 10 cases they had returned to the level before treatment; in 4 cases the pressure showed a further drop. The hypotensive action of $R$. Serpentina was, therefore, perceptible in 91 per cent of my cases for two weeks and in 74 per cent for four weeks after discontinuance of the drug.

\section{After a Second Course of R. Serpentina}

In order to test the drug for consistency of action, all the 50 cases of my series were subjected to a second course of serpina tablets after an interval of four weeks. The tablets were administered in the same doses, but for two weeks only. The results of this second course were most satisfactory, making allowance for the fact that as many as 36 per cent of the cases were still under the hypotensive influence of the first course of tablets. The average drop of systolic blood pressure after the first course had worked out at $17 \mathrm{~mm}$., the maximum fall recorded in any case being $44 \mathrm{~mm}$. In the case of the diastolic pressure, the corresponding values worked out at $7 \mathrm{~mm}$. and $22 \mathrm{~mm}$. respectively.

After two weeks of the second course, the average systolic fall worked out at $10 \mathrm{~mm}$., the maximum drop in any case being $24 \mathrm{~mm}$. The corresponding values for the diastolic pressure were $5 \mathrm{~mm}$. and $12 \mathrm{~mm}$. respectively.

The blood pressure behaviour after the second course of tablets was very similar to that after the first, in the great majority of the cases. However, in one case there was a drop of pressure during the first course but a rise during the second; the reverse happened in one case.

\section{Toxic EFFECTS AND Reactions FROM R. SERPENTINA}

After having used the dried root of $R$. Serpentina in several thousand cases of high blood pressure, both in hospital and private practice, I can vouch for the non-toxicity of the drug with confidence; I have, so far, not come across a single fatality from the administration of this preparation. Even when the administration has been continued without a break for as long as two to five years (as in some of my cases), and even in the presence of cardiac or renal complications, there have been no ill-effects of a serious disabling or permanent nature.

The following reactions were reported by some of my cases, during the present investigation.

$$
\begin{aligned}
& \text { Excessive drowsiness or "sleepiness" } 6 \text { cases } \\
& \text { Feeling of depression or lassitude .. } 4 \text { cases } \\
& \begin{array}{llllll}
\text { Diarrhœa } & \ldots & \ldots & \ldots & \ldots & 3 \text { cases }
\end{array} \\
& \begin{array}{llllll}
\text { Anorexia } & \ldots & \ldots & \ldots & \ldots & 3 \text { cases } \\
& & \ldots & \ldots & \ldots & 2 \text { cases }
\end{array} \\
& \text { Nausea and vomiting } . . \quad \text {.. } \quad . .2 \text { cases } \\
& \text { Vertigo or giddiness } \ldots . . \quad \ldots . \quad \ldots 2 \text { cases } \\
& \text { Increase of polyuria and nocturia .. } 2 \text { cases } \\
& \text { Abdominal griping pain .. } \quad . .1 \text { case }
\end{aligned}
$$

The commonest disturbance after $R$. Serpentina administration, in my experience, has been that of 
excessive drowsiness or sleep; to some of the hypertensives suffering from insomnia, this may prove a blessing in disguise. Diarrhœa is usually of a mild order and responds readily to treatment. On the whole, $R$. Serpentina preparations are very well tolerated by patients and appear non-toxic in therapeutic doses. The only contra-indications, in my opinion, are severe or intractable diarrhœeas or dysenteries and cases of hypertension of renal or malignant type, where this form of treatment proves of no avail.

At the present time, $R$. Serpentina preparations, as manufactured in India, have one serious drawback to their use; not being properly standardized or assayed, the hypotensive action of the drug is not strictly constant from batch to batch of the drug. For some time now, the physicians of this country have felt the need for a more satisfactory and standard preparation of this drug, the action of which can be predicted at all times.

\section{Summary AND Conclusions}

The hypotensive action of Rauwolfia Serpentina (N.O. Apocynaca) has been subjected to clinical trial in a series of fifty cases of essential benign hypertension. Tablets of the dried root of this plant were prescribed in optimum doses, the patients being subjected to periodical check-ups of the blood pressure, according to a pre-arranged plan.

Within a week of $R$. Serpentina therapy, 77 per cent of my cases showed a drop of systolic blood pressure ranging from 2 to $38 \mathrm{~mm}$., with an average drop of $13 \mathrm{~mm}$. A drop of $10 \mathrm{~mm}$. or over was noted in $\mathbf{4 0}$ per cent of cases.

In the case of the diastolic blood pressure, 73 per cent of cases displayed a drop ranging from 2 to $18 \mathrm{~mm}$., with an average drop of $6 \mathrm{~mm}$.; a diastolic response of $5 \mathrm{~mm}$. or over was noted in 35 per cent. In 73 per cent of cases, there was a drop of both systolic and diastolic blood pressure after one week of therapy.

After four weeks of $R$. Serpentina therapy,
85 per cent of cases displayed a drop of systolic blood pressure varying from 2 to $54 \mathrm{~mm}$. with an average of $21 \mathrm{~mm}$. A systolic drop of $10 \mathrm{~mm}$. or over was noted in as many as 74 per cent of cases.

In 81 per cent of cases, the diastolic pressure showed a drop of 4 to $34 \mathrm{~mm}$. with an average of $11 \mathrm{~mm}$. A diastolic fall of $5 \mathrm{~mm}$. or over was noted in 72 per cent.

In 62 per cent of cases there was a " moderate" or "marked" drop of both systolic and diastolic pressure levels.

According to the behaviour of the blood pressure, I was able to recognize five types of response to $R$. Serpentina therapy, which have been described.

The hypotensive action was apparent in 91 per cent of cases two weeks after stoppage of all treatment and in 74 per cent even after four weeks of no treatment.

A second course, of two weeks, was tried in all the cases after an interval of four weeks; the blood pressure response to the second course of tablets was almost as good as during the first.

$R$. Serpentina appears to be a perfectly safe remedy, devoid of any serious or toxic ill-effects. Amongst the few unpleasant symptoms encountered during its administration, were excessive drowsiness (in 12 per cent), lassitude (in 8 per cent), diarrhœa (in 6 per cent), anorexia (in 4 per cent) and nausea with vomiting (in 4 per cent).

On the whole, the results of $R$. Serpentina therapy, in the present series, have been most encouraging. In most cases it was proved capable of lowering both systolic and diastolic blood pressure. Although its action is temporary in many cases, it can be reproduced successfully by a second administration of the drug. No serious reactions to therapy were encountered in any of the cases. $R$. Serpentina, therefore, satisfies all the criteria of a successful hypotensive agent formulated by Evans and Loughnan (1939). Judging from the results of the present investigation, it has a definite place in the treatment of cases of high blood pressure.

\section{REFERENCES}

Ayman, D. (1931). J. Amer. med. Ass., 96, 1852. (1932). Ibid., 98, 545.

Bhatia, B. B. (1942). Jour. Ind. med. Ass., 2, 262. Chopra, - (1933). Indigenous Drugs of India, Calcutta. Evans, W., and Loughnan, O. (1939). Brit. Heart J., 1, 199.

Kapernick, J. S. (1943). Amer. Heart J., 26, 610.
Paranjpe, A. S. (1942). Med. Bull., 10, 135.

Roy, P. C. (1931). Patna J. Med., 4, 131.

Sen, G., and Bose, K. (1931). Ind. med. World, 2, 194.

Siddiqui, S., and Siddiqui, R. H. (1931). Jour. Ind. Chem. Soc., 8, 667.

Vakil, R. J. (1940). Med. Bull., 8, 15. (1942). lbid., 10, 177. 